Nunes, Flávio (2005). Aveiro, Portugal: making a digital city. Journal of Urban Technology, 12(1), pp. 49-70.

\title{
Aveiro, Portugal: Making a Digital City
}

Flávio Nunes

University of Minho - Department of Geography (Portugal, Guimarães)

\section{Introduction}

In recent years, attention is increasingly being drawn to the investigation of how the economic, social and cultural aspects of cities interact with the proliferation of advanced computer-based telecommunications networks. Therefore, the co-evolution of cities and telemediated interactions is progressively emphasised in academic debates concerning the future of cities. As a result, the digital city concept has been defined as a means of creatively integrating telecommunications into urban policy and planning practices and strategies, in order to develop more inclusive and sustainable urban futures ${ }^{1}$.

One of the first contributions to this debate was made in 1994, when William Mitchell published the City of Bits (13). In this book he suggested an exploratory vision by which the remote interactions, provided by the diffusion of information and communication technologies (ICT) in contemporary societies, would gradually transform urban form and function, in such a way that he points out the need to enlarge our conceptions of urban planning in order to include virtual places as well as physical ones. In a later work (14), Mitchell clarified that this recent wave of urban infrastructural networking will not create 
entirely new urban patterns from the ground up, but refashion the urban patterns that emerged and had been made possible and sustained by previous networks (transportation, water supply, electric power supply or telephone networks). In other words, the city should be seen as a complex and dense place of human activities interrelated by pedestrian circulation and mechanized transportation, as well as a network place within which digital information can flow speedily and freely.

A few years after the appearance of the City of Bits, when the digital infrastructure development had taken some time to produce considerable effects, and it was clear that the need for face-to-face interactions would not be destroyed but just significantly altered by digital technologies, Haron (10) focuses on how digital technology can be incorporated into the rearrangement of our homes, offices, communities and cities, in order to achieve optimal forms of space. In the context of research, the author presented practical examples and suggestions (based on successful and failed experiences) for urban managers who seek to capitalize on the potentials of the digital electronic era. With this approach he "treats the emergence of digital places not as a phenomenon to be observed but as a development to be affected and improved by the application of appropriate design principles" (10, p. 6).

The discussion about these practical projects and suggestions is increasingly relevant in such an embryonic field in terms of policies ${ }^{2}$, since the arguments of recent studies show us that the use of telecommunications to create pleasant places is a simplistic vision that must be considered with special attention. Graham and Marvin (9) presented a critical view on this subject based on a deeper analysis of changing infrastructure networks, especially telecommunications, in contemporary urban areas, and clearly demonstrated that electronic

\footnotetext{
${ }^{1}$ In other words, digital cities can be considered as "community-based networks" (2, p. 144), or networked communities, pursuing a strategic vision that involves the use of ICT's in new and innovative ways to empower its residents, enterprises, institutions and the city as a whole.

${ }^{2}$ Especially when "new telecommunications initiatives are still often intimately connected with utopian and deterministic ideas of technology's beneficial and liner impacts upon the social, environmental and spatial development of cities" $(8$, p. 15).
} 
networks, far from equalizing opportunities, may act as a force for creating divisions and segregating less favoured areas, reinforcing and recreating new forms of socio-economic exclusion. As a result of this conclusion, there is a general agreement that positive actions, on the basis of a strong political commitment, are needed to ensure that urban managers use the full potential offered by the complex links between urban life, the development of urban places and the use of communications technologies.

However, our main purpose with this paper is not to review a set of local innovative projects and their effects in terms of shaping positive synergies between electronic interactions and urban development. We wish to focus on the creation process of a Digital City as a global programme, in order to put forward the factors for success and failure during the implementation of these types of political programmes.

This paper attempts to explore the fast-growing wave of urban experimentations with telecommunications, which are currently emerging across the pioneering and most successful Portuguese Digital City (Aveiro). The main purpose of this analysis is to draw conclusions on the broader question of choosing the best policy orientations to shape more efficiently the coordination between the changing form and socio-economic development of cities and the spread of electronic interactions within such cities.

This case-study attempts to reflect the importance of the national political priorities as fundamental factors shaping the information society at a local level, but it also tries to fit in the newer strands of technology research in social sciences that focus on the context dependency of the uptake technologies, demonstrating that ICT application is embedded in existing economic, institutional, social and spatial structures (18). In this context, we will begin our analysis by presenting the evolution of Portuguese policy priorities for the setting up of digital cities. After that, and concerning the case-study, we will analyse the official estrategy documents, the available information concerning the evaluation of this initiative, and 
other information retrieved from several sources presented at the bibliographic references, complemented by qualitative information provided by interviews with the managers of the Aveiro Digital City Programme.

\section{Initial process of the Aveiro Digital City pilot programme (1998-2000)}

The first references to the creation of an Information Society in Portugal were made by the $13^{\text {th }}$ Portuguese Constitutional Government (1995-1999). In 1996, a Committee for the Information Society ${ }^{3}$ was created, and its main task was the preparation of a Green Paper. This document was approved in April 1997, combining a wide range of major strategic options and a coherent body of concrete measures to implement the information society in Portugal.

Following the approval of this strategic document, several task forces were set up to establish different programmes to materialize the identified strategic measures. In this context, the Digital Cities Programme was launched in February 1998 by the Ministry of Science and Technology, as the first political initiative to develop the information society at local levels, aiming at spreading its benefits throughout Portugal.

In the first phase (1998-2000), Digital Cities was implemented as a pilot programme, which would eventually cover all the cities in the country during the second phase (2000-2006). For this purpose, a set of two rural regions was selected, and also one metropolitan area and five small and middle-sized cities ${ }^{4}$. Each of these had different characteristics in order to collect diversified lessons about the carrying out process of several demonstration projects, with

\footnotetext{
${ }^{3}$ Members of this Committee included experts appointed by several Ministries.

${ }^{4}$ In the Lisbon Metropolitan Area a project was developed in order to support social integration policies in a large and expanding conurbation. The two remote rural regions were Alentejo and Trás-os-Montes, where projects were designed to create new opportunities for the local population, fight social and economic disparities and promote regional networking. Bragança, Guarda and Castelo Branco are three peripheral cities that intended to mobilize resources in order to fight the effects of being located away from the most dynamic and urbanised area of Portugal. Marinha Grande is an industrial city specialized in moulds and dies industry, which tried to promote projects to increase productivity and improve the competitiveness of this economic cluster. Finally,
} 
different applications ranging from combating social exclusion, increasing urban living conditions, bridging the gap between inland and coastal areas, promoting employment and economic competitiveness.

In this paper, we will focus only on the Aveiro Digital City case-study for two main reasons. On the one hand, it is the most enduring experience ${ }^{5}$ of a Portuguese digital city and is considered as the most comprehensive and successful of all; on the other hand, it is based on a more reliable digital city concept in comparison with other experiences.

With a population of about 55 thousand inhabitants, Aveiro is a port city located near the Vouga estuary, some $60 \mathrm{~km}$ southwards from Porto. From all the experiences that were encouraged, this city soon appeared to have several conditions that made it a political option, providing the opportunity to evaluate concepts and dynamically test new ideas of ICT applications as tools for local development.

There is another important reason for the selection of this case-study, and it has to do with the cross-sectional perspective that supports this initiative. While others Portuguese digital cities have been developed with specific purposes (for instance: fighting social exclusion, improving economic competitiveness or trying to reduce the disadvantages of inland cities), the Aveiro Digital City has, on the contrary, been developed in order to improve living standards and urban life quality in all its dimensions, by the participation of all local agents and the use of ICT's as acceleration tools for a community sustainable development process, in economic, social and cultural aspects (Table 1).

The main idea consisted in developing a flexible programme, aiming at a progressive and broad mobilization of society with a strong institutional and public participation, with the

Aveiro is a coastal city in the central Portugal where projects were designed to integrate several services through telematics networks, in order to improve the city life in all its aspects.

${ }^{5}$ The idea of creating a national digital cities political programme appeared during a visit, in November 1997, of the Minister of Science and Technology to the telecommunication research centre in Aveiro, in which he heard about practical results of ICT application projects, not in technicians' speeches but in the perspective of the final users (teachers, medical doctors, social assistances, parents of hospitalised children's...). 
consequent formalization of new objectives and the constant addition of new projects spontaneously arranged between local agents. With this approach, the idea was to achieve an ongoing and adjustable digital city construction, with the continuous development of new solutions for the link between the technological and the socio-cultural domains.

The programme was structured according to a set of eight complementary intervention areas. For each of these areas, the board presented concrete objectives that were to be achieved by the execution of practical projects, using a complete funding system from 1998 until 2006, with the possibility of a mid-term review at the end of the first phase ${ }^{6}$.

During the pilot programme phase (1998-2000), 38 diversified projects were developed, from a total of 40 approved projects. The 38 projects involved an investment of almost 5 million and 600 thousand Euros (94\% of the predicted investment), which correspond to approximately 147 thousands Euros per project (Table 2). About 65,3\% of all the money invested was supplied by the Portuguese Government and co-financed by the European Union.

Services for commerce and industry and local e-government were the two intervention areas receiving the largest portion of this investment. On the contrary, and analysing the allocation of budgets per project, we can conclude that the social exclusion aid services and entertainment, culture and arts were the two intervention areas with the lowest budget per project. Both these intervention areas involved also the lowest participation of proponents in the total investment, and they were consequently more dependent on public funding. Analysing the distribution of funds by intervention area, it can also be seen that only one university-based project was developed, using $4 \%$ of the available funds, despite the University of Aveiro's well-known importance for the city life and for the programme coordination. While these figures can suggest the need for stronger partnerships with other

\footnotetext{
${ }^{6}$ In 2000, at the beginning of the Third EU Community Support Framework 2000-2006
} 
urban entities, it can also reveal the existence of independent funds in university to support the inclusion of ICT in its organizational procedures.

\section{Perceived factors for success/failure in the Aveiro Digital City pilot programme (1998-} 2000)

In this section we will try to identify some of the main factors for success gathered from this initial experience, but we will also explore the constraints that appeared during the initial process, which should be avoided in a subsequent phase and in other cities on the verge of their digital challenge.

\section{Technological infrastructures}

Even before the beginning of this programme, Aveiro was already profiting from a fully digitalized telecommunications network, a broadband access infrastructure to support R\&D projects, and it was also linked to the RCTS (Science, Technology and Society Network). The RCTS consists of a major reinforcement of the network's bandwidth, linking higher education and research institutions throughout the country, aiming at the creation of synergies between communities and the academic and scientific world.

Because of its conceptual basis and also due to this infrastructural background, the Aveiro Digital City intended to be more than a merely technological programme, trying to act as a programme for the mobilization of society and aiming at the promotion of noticeable and radical changes in the citizens' behaviour and in the institutions' performance. Nevertheless, if we analyse the results obtained in the first phase, we can conclude that, unlike what had been proposed, the priority of these investments was the diffusion of ICT infrastructures throughout the city's institutions. This was assumed as a preliminary condition to further developments in the programme, and as a result, while good levels of institutional awareness 
for the benefits of ICT applications were achieved, on the other hand, a low level of citizens' participation on the supported activities was clearly noticeable.

\section{Public participation}

Moutinho and Heitor (16) having studied in more detail the activities carried out in the context of these projects, presented a conclusion suggesting that investments orientated towards the participation and mobilization of citizens for the information society were practically inexistent, and, in general, ICT infrastructures and ephemeral digital contents were the most important components in the projects execution.

As a result of this option, and at the end of the first phase, the evaluation of many activities revealed reduced levels of public participation. Therefore, the evaluators call the attention to the fact that, in the future, it is necessary to maximize visible and useful on-line services, with direct impact on the improvement of the citizens' quality of life. In order to promote a higher participation of the digital city's final users, investments in promotion and publicising actions, differentiated according to the specificity of all targets, should also be considered in future activities, with the purpose of mobilizing the general population.

\section{Previous experiences in ICT applications}

The creation of a digital city is a long adjustment process involving a gradual, persistent and determined intervention. In this case study, this political programme did not appeared as a totally new challenge, as it was based on several previous experiences developed by three local institutions.

Firstly, there is a telecommunications research centre placed in Aveiro since 1950 (from the Portuguese telecommunications operator, PT Telecom), well-known as a national and international reference in telecommunications researches. This research unit was involved in 
initial pilot projects, whose purpose was to evaluate ICT applications as potential instruments for the development process of the less favoured regions. For instance, in 1992, a broadband network was established in two rural villages. The idea was to allow for e-learning experiences and e-health care experiences even before the appearance of the internet. In that same year, a broadband network was set up to support video conference communications between eight homes for elderly and a local charitable institution.

Secondly, there is also a local authority engaged in technical and administrative modernization experiments, with a special interest in ICT applications. For instance, in 1988, with the technical support of the local telecommunications research centre, a video conference system was connected between the City Council and a small locality in the municipality, which is isolated by the Aveiro Estuary (São Jacinto). Aveiro was also the first Portuguese City Council to offer an interactive kiosk (based on ISDN technology) available for public use.

Thirdly, Aveiro has an innovative and active local university in areas that are relevant for the programme (such as telecommunications, information technologies, urban planning, art, and communication, as well as education and training or sociology of organizations). In this context, the university is trying to be an example of ICT use for administrative modernization. Telecommunications was actually the first degree promoted by this university, 30 years ago. The presence in Aveiro of these three key institutions with experience and interest in ICT applications and their availability to set off and lead the programme was definitely a factor for the success of this pilot programme.

\section{Institutional density}

Apart from these basic institutions for the strategic command of the programme, Aveiro had also a local business environment with several firms working in technologically advanced 
areas, and many other local entities interested in developing activities covering several different aspects of the use of ICT's.

As a result of the successful mobilization of society, local consortiums were formed to develop each of the 38 projects, involving a total of 74 diversified local entities (Figure 1). The institutions that were more involved in the construction of the digital city and more receptive to the application of ICT's into their routine activities were mainly social welfare institutions, ICT local firms and education institutions (from all levels).

Despite this mobilization, at the end of the first phase it was assumed that the principle of partnership must be deepened in the next stages of the construction of the digital city. It must be emphasized that this strategic ambition is strictly dependent on the strengths conjugation of all local agents, which are the driving forces for the modernization process of a community.

\section{Human resources (know-how)}

The success of ICT's integration in local entities, aiming at better efficiency standards by means of the modernization of processes and services, demands for the future a better evaluation of the internal challenges inside these organizations, specifically concerning the availability of enough human resources with specific skills to perform efficiently these new services and responsibilities.

\section{Horizontal integration}

In this embryonic phase, it seems that each project was conducted independently, as a means for the dissemination of new services and competences, and that the intra-projects coordination was neglected. The only situations of shared experiences occurred at the end of the first phase, for purposes of public promotion, dissemination of results and definition of future projects, specifically during the week of the "Aveiro Digital City Exhibition" and the 
“Aveiro Digital City Forum" meeting, when each of the eight intervention areas operated as platforms for work experience exchanges.

In the future, efforts must be made in order to interconnect the networks and services that were created, thus generating a more consistent global programme. This coordination activity is definitely a challenge, especially when we are dealing with an enormous group of local institutions, without cooperation habits and with different interests and objectives.

\section{Vertical integration}

In Portugal, only national strategic measures will allow for some administrative modernization processes and for the subsequent appearance of useful services to answer the citizens' needs (taxes, elections, public tenders...). From the citizens' point of view, a more efficient programme demands a deeper coordination between local and central initiatives.

\section{Bureaucracy and Access to Funds}

The disadvantages of the Portuguese public administration's centralized model somewhat compromises the predefined objectives ${ }^{7}$. This constraint was responsible for a problematic start, characterised by budget allocation negotiations and bureaucratic relationships between local entities and the government institution responsible for the financing decisions (Foundation for Science and Technology).

The structure of public funding was definitely the most problematic question in this experimentation stage, especially in terms of the inadequacy between the timing of the financing supports and the actual developments. To better understand this problem, we must have in mind that the Digital City Programme was not planned and appeared during the Second EU Community Support Framework (1994-2000), and therefore, in order to initiate this project, the Minister in charge had to transfer funds from the Telecommunications 
Operational Programme to the Foundation for Science and Technology, which was an institution without any experience whatsoever in managing these kinds of funds and projects. This process led to prolonged delays in the beginning of the financing process, unbalanced financing sequences, unexpected budget cuts, and, consequently, the projects amputation during the implementation phase. Almost all funds were made available in just one year, and between 1998 and January 2000 only 5\% of the final investment were actually channelled to the projects ${ }^{8}$.

This constraint might be avoided in the future with some competences reformulations within the organisational model. But while it is true that the public funds corresponded to $65 \%$ of the total investment (showing good levels mobilization by the private sector), it is also true that the beginning of the projects was highly dependent on these funds. This was clearly an obstacle, which should be avoided in future by combining multiple investment sources in a more integrated model in terms of financing.

In terms of practical financing allocation, there were also some concrete problems as concerns the need to fulfil specific documentation norms to justify expenses with the performed activities, resulting from a recognized lack of experience of local institutions in these kinds of requests. This was locally taken as a setback for the execution of the projects - for instance, one of the approved projects was cancelled (the Net Rotary project) by its coordinator, as he admitted not having the necessary skills to deal with all the necessary documentation. In the future, these bureaucratic procedures should be simplified, using for instance ICT's potentialities within the programme's procedures.

\section{Organisational model}

\footnotetext{
${ }^{7}$ In Portugal there are not regions with administrative autonomy.

${ }^{8}$ The programme started in 1998 but Aveiro received the first financial support only in June 1999, and some projects started their activities only in January 2000.
} 
While in the beginning this was expected to be a flexible programme, aiming at a continuous formalization of new objectives and the inclusion of new projects spontaneously arranged between local agents, the truth is that during the process the interveners realised that in order to achieve this aspiration the public funds should be concentrated in the local command organisation, which should be responsible not only for the strategic guidance of the programme but also for the management of funds and allocation options.

It seems clear that, for the next stages, an administration model with new political and operational competences should be created, in order to obtain a more versatile and flexible programme, with financial autonomy.

\section{Monitoring process}

Even if a Monitoring Agency, designated by the Ministry for Science and Technology, had been anticipated right at the beginning of the process, the fact is it only began operating in the summer of 2000 as a result of a few meetings between the Aveiro Digital City Consortium and the 38 Projects Coordinators (one meeting for each intervention area), whose results were presented at the "Aveiro Digital City Forum". Of course, this subsequent evaluation was unproductive in terms of providing a helpful ongoing correction of methodologies and procedures in accordance with the initial objectives.

These meetings were promoted in a self-assessment perspective, and especially conducted to identify the future course of the programme from the point of view of the entities involved.

\section{Self-sustainability}

Changing procedures, which is the main objective of a digital city programme, is a long adjustment process requiring a gradually and persistent intervention in an evolution process related to building competences. However, one fundamental limitation observed during the 
first phase was the absence of conditions for long term sustainability of the new services provided to citizens. As we will see, and unlike what was initially proposed, for several circumstances there was not a linear sequence between the first and the second phase of the programme, almost all these initiatives were abruptly stopped, and, consequently, all the initial financial and organizational efforts did not have a desirable progression. Moutinho and Heitor (16, p. 14) underlined that "when the limited public funds ended, some of the projects came to a close, while others kept their presence on the Internet, although rarely updated".

\section{A problematic transition to the next phase (Aveiro Digital Programme 2003-2006)}

Despite the reduced time frame of the pilot project and the extent to which public funds were continuously available, the practical results exceeded the expectations put forward during the projects submission (Figure 2), revealing a strong commitment and mobilization of resources towards the accomplishment of the planned objectives.

As we have already pointed out, despite this quantitative success, at the end of 2000 everybody seemed to agree that there were few situations in which there was a direct impact on the modernization of processes and in terms of new and useful services for the Aveiro citizens. By that time it was quite clear that the process of creation of the Aveiro Digital City had only begun, and it was assumed that all strategic objectives delineated in 1998 were still real and valid and should be accomplished in the years to come, also because some of them did not benefit from any investment. Surprisingly, the second phase, which was planned to start in January 2001 and to last until December 2006, has only begun in September 2003 with the selection of 40 new projects, involving 134 local and regional entities and a global investment around 14,6 millions Euros. For this almost three year delay we can point out two main reasons. 
Firstly, during 2001 the last Portuguese Government was formatting the Cities and Digital Regions Measure (presented in October 2001), to be supported by the Operational Programme for the Information Society (financed by the Third Community Support Framework 20012006). This delay in the arrangement of this new political measure is very criticised and can only be explained by the fact that it was necessary to wait for the conclusion of other Portuguese pilot programmes, in order to have more data to sustain this new strategic measure.

Secondly, at the end of 2001, and against all odds, a date was set for extraordinary elections, which conducted to the change of Portuguese Government in March 2002. The new managing team of the Operational Programme for the Information Society was designated only in September 2002, and implied relevant changes in the political objectives of the Programme. In the Cities and Digital Regions' political measure, instead of urban projects, developed by each municipality, the new Government chose to support projects within the sub-regional scope and controlled by supra-municipal entities (ex: associations of municipalities) ${ }^{9}$, as a way to disseminate ICT applications throughout the country and promote economic competitiveness, increase welfare standards and consequently reinforce the regions' internal cohesion.

In order to contribute to the transition to the second phase, the Aveiro Digital City Consortium prepared a project (Estaleiro 2001) that would operate until the end of 2001, but, as a result of this problematic transition, it was extended until the end of 2002, as a way of preserving the technical team and maintaining the main equipment of the previous phase (Montra Aveiro Digital). The Montra Aveiro Digital allowed for the public to have access to

\footnotetext{
${ }_{9}^{9}$ Besides this general orientation, the strategic guide to facilitate a deeper harmonization in the projects' submission and evaluation was only presented in September 2003, when 40 projects were already selected in the first public tender for Aveiro Digital 2003-2006.
} 
ICT infrastructures during these two years ${ }^{10}$ and the promotion of some horizontal initiatives close by citizens of Aveiro.

Despite the importance of the Estaleiro 2001, it is obvious that this extended interruption, caused by external reasons, implied great disadvantages for the creation process of the digital city in Aveiro, especially because we are dealing with a challenge that involves a gradual and persistent intervention in order to change routines, create skills and modify procedures. Therefore, the renovation dynamics, clearly present in that area during the year 2000, was broken, and some investments were definitely wasted.

The only factor avoiding a total retrocession way back to the starting point was a nonmeasurable indirect impact of the funds applied in the first phase, specifically because of the fact that the implementation of the process was not carried out by the three main proponents, but instead by a large number of local entities. This strategy has led to good levels of institutional awareness for the benefits of ICT applications.

In spite of all these obstacles, the second phase started and we can already point out several relevant differences, which can be grouped into three main domains: the organizational model, the geographical extension and the strategic guidance.

As regards its organization, the Aveiro Digital Programme 2003-2006 is led by an Executive Commission, which was created in a protocol established between the Aveiro Digital Association (constituted in January 2002 as a way to integrate in a more effective way the three initial local proponents of the programme and the other entities engaged in the first phase) and the Association of the Estuary Municipalities. However, and despite what previous experiences have taught us, specifically in terms of the problematic financial allocation performance of the previous phase, and mainly as a consequence of the Portuguese centralized administration, this Executive Commission is not responsible for the management of funds.

\footnotetext{
${ }^{10}$ In 2001 and 2002 the average of the Montra Aveiro Digital was around 3500 users per month.
} 
Geographically, this programme goes as far as the region of the Association of the Estuary Municipalities, composed by 11 municipalities and 340 thousand inhabitants. This enlargement was a condition imposed by the managing team of the Operational Programme for the Information Society, but a territorial extension of the programme was already anticipated at the time when the Aveiro Digital Association was established.

Strategically, the Aveiro Digital Programme 2003-2006 is guided by the same concept and the same eight intervention areas set up in the first phase, but it is structured not in general guiding objectives but as a set of 42 totally explained projects ${ }^{11}$, to be developed by local consortiums arranged between local and regional entities ${ }^{12}$. Despite being legitimised by the conclusions on the first phase of the programme, provided by an Independent Evaluation Committee and also by the wider discussion between the locally involved entities and carried out at the end of the first phase (about what initiatives should be conducted in the future), the Aveiro Digital Programme 2003-2006 definitely obeys a more rigid and conditioning strategy, especially if we look at the initial expectations, which pointed to a flexible and open programme, with a constant inclusion of new projects, spontaneously arranged between local agents.

\section{Conclusion}

To conclude our analysis of the problematic experience that has been characterizing the Aveiro Digital City Programme, we can underline three risks that should be avoided during the implementation of digital cities.

Favouring the diffusion of ICT infrastructures as well as the production of ephemeral contents throughout local entities may be positive as a way to guarantee good levels of institutional

\footnotetext{
${ }^{11}$ With reference to the concrete marks to be reached in each one of them.

${ }^{12}$ In addition to these 42 proposal projects, the Executive Commission is responsible for the implementation of six structural and horizontal projects for the first intervention area (Building a Digital Community).
} 
awareness for the benefits of ICT applications, but it may have a negative impact in terms of a small participation and mobilization of citizens for the information society.

Presenting and supporting a large variety of practical projects, which for some reason may have to be interrupted (for instance by the lack of financial support or the need to geographically extend the effects of the initiative) is extremely negative, since we are dealing with a difficult purpose - creating new competences and reshape routines. Setting up conditions for long term sustainability of new services provided to citizens is crucial for the success of these kinds of initiatives, which impose systematic and persistent interventions led by human resources with specific skills.

Aiming to achieve a consistent and coherent digital city should involve an organizational model with real competences (also in terms of budget allocation negotiations) and a strong supervision, especially since we are facing a network of local agents developing individual projects and without cooperation habits.

If one avoids these setbacks during the implementation of a digital city, we believe that there will be a chance to achieve better results in terms of the integration of telecommunications into urban policy and planning practices. 


\section{References}

(1) CAD, Relatório Global da 1ª Fase do Programa Aveiro Cidade Digital 1998-2000 (Aveiro: Consórcio Aveiro Digital, 2001) <http://www.aveiro-digital.pt/arquivo/docs/Rel_GlobalACD1998_2000.pdf $>$ (Accessed February $3,2004)$

(2) M. Castells, The internet galaxy. Reflections on the internet, business and society (New York: Oxford University Press, 2001)

(3) CEAD (a), Apresentação dos Projectos Aveiro Digital 2003-2006 (Aveiro: Comissão Executiva Aveiro Digital, 2003) <http://www.aveiro-digital.pt/default.asp?func=1-18-2> (Accessed February 3, 2004)

(4) CEAD (b), Programa Aveiro Digital 2003-2006 (Aveiro: Comissão Executiva Aveiro Digital, 2003) $<$ http://www.aveiro-digital.pt/apresentação/doc/programa.pdf> (Accessed February 3, 2004)

(5) CMA; UA and PT, Programa Aveiro Cidade Digital (Aveiro: Câmara Municipal de Aveiro, Universidade de Aveiro and Portugal Telecom, 1998) <http://www.aveiro-digital.pt/arquivo/docs/programa.rtf $>$ (Accessed January 31,2004$)$

(6) A. Correia, Moving towards an Information Society in Portugal (Lisboa: Universidade Nova de Lisboa, 1999) <http://www.isegi.unl.pt/DOCENTES/acorreia/preprint/Spainpaperweb.htm> (Accessed February 8, 2004)

(7) L. Gouveia and J. Gouveia, Towards a social approach to digital cities (Porto: Universidade Fernando Pessoa, 2002) <http://www.ufp.pt/ Imbg/com/gd_newwork02.pdf> (Accessed March 12, 2004)

(8) S. Graham and S. Marvin, "Planning cyber-cities? Integrating telecommunications into urban planning," Town Planning Review 70:1 (1999) 89-114

(9) S. Graham and S. Marvin, Splintering Urbanism. Networked infrastructures, technological mobilities and the urban condition (London: Routledge, 2001) 
(10) T. Horan, Digital Places. Building our city of bits (Washington D.C.: Urban Land Institute, 2000)

(11) MCT, Programa Cidades Digitais (Lisboa: Ministério da Ciência e da Tecnologia, 1998) $<$ http://www.mct.pt/CidadesDigitais/prgcdig.htm $>$ (Accessed February 12, 2001)

(12) MCT, Programa Operacional Sociedade da Informação (Lisboa: Ministério da Ciência e da Tecnologia, 2000) $<$ http://www.mct.pt/qca/posi/posi.htm> (Accessed February 14, 2001)

(13) W. Mitchell, City of Bits: Space, Place and the Infobahn (Cambridge: MIT Press, 1994)

(14) W. Mitchell, E-Topia: "Urban Life, Jim - But Not As We Know It" (Cambridge: MIT Press, 1999)

(15) G. Moreira, E-government in local level in Portugal (Lisboa: Universidade Técnica de Lisboa, 2003)

$<$ http://www.brookes.ac.uk/schools/planning/conference/papers\%20pdf/moreira.PDF> (Accessed March 8, 2004)

(16) J. Moutinho and M. Heitor, Digital Cities and the challenges for a knowledge-based view of the territory: evidence from Portugal (Lisboa: Universidade Técnica de Lisboa, 2003) <http://in3.dem.ist.utl.pt> (Accessed May 12, 2003)

(17) M. Palacios, Internet as system and environment in cyberspace: preliminary ideas from an ongoing research (Salvador: Universidade Federal da Bahia, 2003) <http://tripleC.uti.at> (Accessed March 8, 2004)

(18) A. Van Der Meer and W. Van Winden, "E-governance in cities: a comparison of urban information and communication technology policies," Regional Studies 33:4 (2003) 407-419 
Table 1. The main goals of the Aveiro Digital City pilot programme (1998-2000)

Increase citizens' living standards

Reinforce democratic participation

Modernize the local public administration

Reinforce sustainable growth

Promote equal opportunities

Stimulate job creation, social justice and lifelong learning

Integrate handicapped people

Identify the best practices of ICT use for urban development

Source: Câmara Municipal de Aveiro, Universidade de Aveiro and Portugal Telecom (1998) 
Table 2. Aveiro Digital City Pilot programme (1998-2000)

\begin{tabular}{|l|c|c|c|c|}
\hline Intervention Areas & $\begin{array}{l}\mathrm{N}^{\mathrm{o}} \text { of } \\
\text { developed } \\
\text { projects }\end{array}$ & $\begin{array}{l}\text { Executed } \\
\text { investment by } \\
\text { intervention } \\
\text { area }\end{array}$ & $\begin{array}{l}\text { Executed } \\
\text { investment by } \\
\text { project } \\
\text { (euros) }\end{array}$ & $\begin{array}{l}\text { Public } \\
\text { funding }\end{array}$ \\
\hline IA1 - Building a digital community & 5 & $19 \%$ & 208.020 & $69,7 \%$ \\
IA2 - Local e-government & 4 & $20 \%$ & 284.908 & $68,4 \%$ \\
IA3 - School and education community & 7 & $16 \%$ & 129.224 & $63,6 \%$ \\
services & 1 & $4 \%$ & 201.078 & $74,9 \%$ \\
IA4 - University community services & 1 & $5 \%$ & 267.548 & $66,9 \%$ \\
IA5 - Health care services & 4 & $4 \%$ & 54.154 & $78,8 \%$ \\
IA6 - Social exclusion aid services & 6 & $27 \%$ & 228.679 & $52,6 \%$ \\
IA7 - Services for commerce and industry & 10 & $8 \%$ & 45.012 & $77,2 \%$ \\
IA8 - Entertainment, culture and arts & 38 & $100 \%$ & 147.151 & $65,3 \%$ \\
\hline TOTAL & & & &
\end{tabular}

Source: Consórcio Aveiro Cidade Digital (2001) 
Figure 1. Local agents engaged in the 38 Aveiro Digital City projects

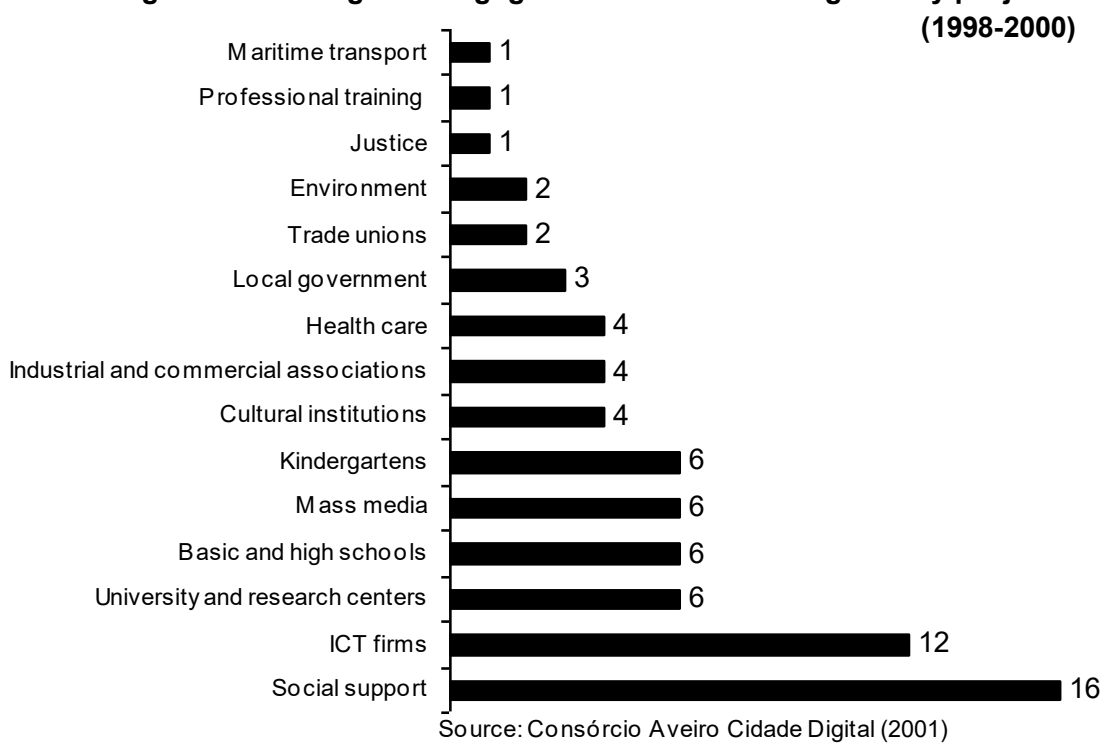


Figure 2. Practical results achieved by the Aveiro Digital City pilot program me (1998-2000)

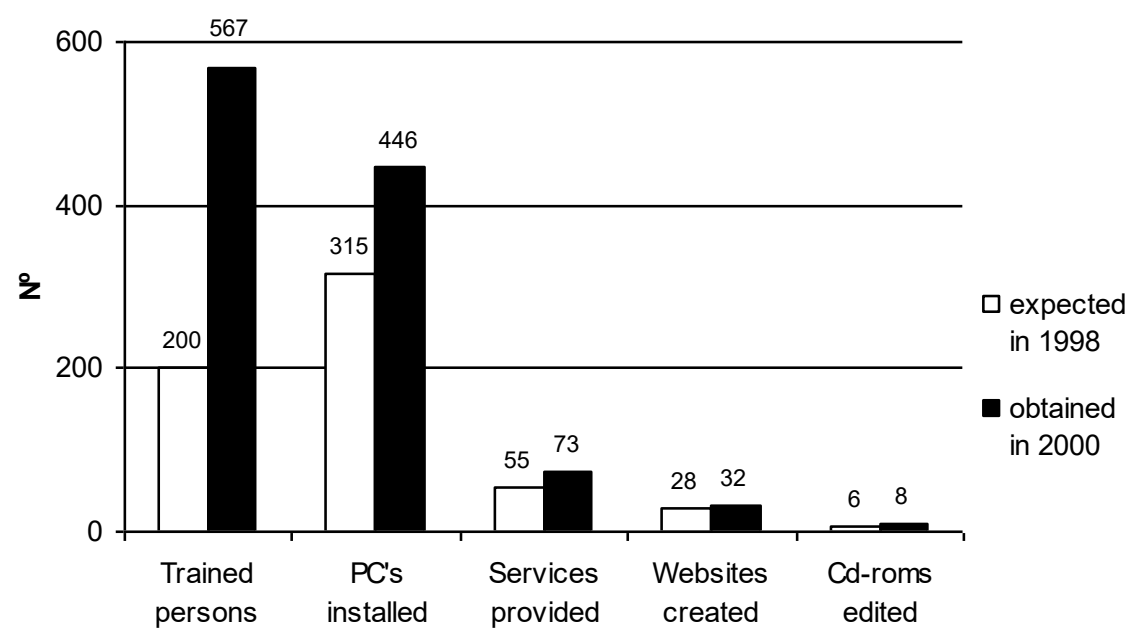

Source: Consórcio Aveiro Cidade Digital (2001) 